\title{
Interview Catharina van Delden, innosabi
}

\section{Interview Question}

Let us think 15 years ahead: Will we as the "user" become even more important in driving innovation in the health care industry? If so, how will we do that? Where are the limitations for open innovation in the health care sector?

\section{Author: Catharina van Delden, innosabi}

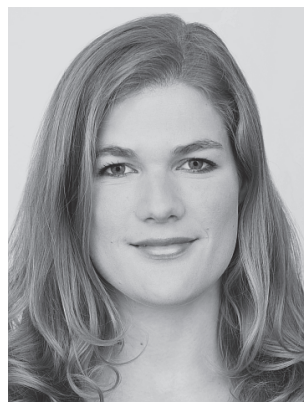

"Catharina went for a $8,2 \mathrm{~km}$ run today" - nine friends like this post on my Facebook profile. Today I cannot only measure my timing and share it on social networks to let others motivate me, I can also check my pulse, monitor my hydration, count my steps, measure my blood pressure - and have all this data analyzed on my smartphone in real time. Individuals of our modern society are more informed than ever before about personal health and are able to understand what influences wellbeing.

But not only the healthy utilize the availability of information and possibilities to connect with others: Especially patients are provided with a proven technology to innovate solutions to their own health problems. A prominent example is Tanya Vlach, who lost her eyesight on the left side in an accident. Being an artist who strongly relies in her vision, she invented the concept of an "in-eye-camera". With an open call she asked engineers to technically realize this idea and afterwards collected money via crowdfunding to actually build it. Tanya is not the only individual innovating in health: Today many patients invent their own therapies, treatments and drugs because they cannot find existing solutions at the market.

In the next step these innovators will share, collaboratively test, adapt and improve their solutions so that even more patients can benefit from these inventions and live a healthier life. We at innosabi will provide them with the tools and technology to realize this vision to its full potential.

Catharina van Delden is CEO and co-founder of innosabi GmbH in Munich; She is also a co-founder of Germany's leading social product development platform unserAller.de. 